\title{
AS FANFICTIONS E AS RELAÇÕES DISCURSIVAS NO CIBERESPAÇO: PARTICIPAÇÃO SOCIAL POR MEIO DA LÍNGUA INGLESA ${ }^{1}$
}

\author{
Fanfictions and discursive relations in the cyberspace: social participation through \\ the English language
}

\author{
Felipe Sousa ADATI \\ Universidade Estadual de Londrina (UEL), Paraná, Brasil \\ Felipe TREVISAN FERREIRA \\ Universidade Estadual de Londrina (UEL), Paraná, Brasil \\ Vera Lúcia Lopes CRISTÓVÃO \\ Universidade Estadual de Londrina (UEL), Paraná, Brasil
}

\begin{abstract}
RESUMO: A literatura, na medida em que é uma expressão artística, catártica e íntima dos pensamentos do autor, é também um ato social; e, como tal, transforma o meio em que é difundida (Cândido, 2000). Ela se transforma diacronicamente a fim de adaptarse ao meio em que se insere ou, pelo contrário, quebrar os paradigmas vigentes. É nesse solo, influenciado pelo advento da internet, que brotam as fanfictions: textos literários criados por fãs de determinado ícone midiático que circulam no ciberespaço e que, apesar de sua despretensão, configuram grandes possibilidades ao empoderamento dos estudantes pela educação. Assim, este trabalho busca apresentar um mapeamento de trabalhos acerca do uso desses textos como instrumentos educacionais e analisar de que modo eles podem contribuir para a atenuação da condição de vulnerabilidade social e para o ensino de Língua Inglesa.
\end{abstract}

Palavras-chave: Fanfiction; Língua inglesa; Vulnerabilidade social

Abstract: Literature is an artistic and cathartic expression of feelings and thoughts as much as it is a social activity. As such, it transforms the social environment in which it is spread (Cândido, 2000). It also transforms itself diachronically in order to adapt to the environment or to change it somehow. In the $21^{\text {st }}$ century, highly influenced by technology, the fanfictions emerge: literary narratives created by fans of a media icon and shared in the cyberspace. Despite their unpretentious character, these texts can be powerful educational tools in developing students' literacies and social participation.

\footnotetext{
${ }^{1}$ Este texto insere-se no Projeto de Pesquisa "LINGUAGEM E SOCIEDADE: POSSIBILIDADES DE PARTICIPAÇÃO SOCIAL DE GRUPOS SOCIALMENTE VULNERÁVEIS POR MEIO DA LÍNGUA INGLESA", cadastrado na UEL sob o número 08581. Meus agradecimentos ao CNPq pelo recurso financeiro durante o período de 01 de março de 2013 a 28 de fevereiro de 2016 relativos à vigência da bolsa de produtividade em pesquisa: PQ2, processo n. 311921/2012-4.
} 
Thus, this paper aims at analyzing the state of the art regarding fanfictions as an educational tool and how the genre can contribute to social participation and to the teaching of English.

Key words: Fanfiction; English teaching; Social vulnerability

\section{Introdução}

O advento da internet na contemporaneidade não só tem transformado as relações sociais, como também tem reinventado continuamente a interação entre comunidades discursivas (Massunaga, 2013). O ciberespaço vem emergindo como um espaço democrático onde indivíduos distantes física e socialmente (isto é, pertencentes a países e/ou grupos sociais distintos) possam contribuir coletivamente para a criação de cultura e conhecimento. Unindo-se e ocupando este espaço, tais indivíduos fazem soar suas vozes, que, muitas vezes são desconsideradas na construção do conhecimento científico ou da cultura dominante (Massunaga, 2013; Bourdieu e Passeron 1970). Isto acontece, por exemplo, quando uma aluna de uma escola pública brasileira cria uma página no Facebook $^{2}$ para compartilhar fotos e opiniões acerca dos problemas que enfrenta no espaço escolar - o "Diário de Classe""3 - ocupando um espaço digital para que sua voz seja ouvida na comunidade online, uma vez que não o era no ambiente escolar.

As fanfictions - ou simplesmente fanfics - estão inseridas neste universo e são parte importante deste processo de socialização situada em ambientes digitais. Elas podem ser descritas como narrativas fictícias criadas e consumidas por fãs de determinado ícone midiático (filmes, livros, seriados televisivos, jogos de videogame, entre outros), circulando em espaços de afinidades digitais, isto é, espaços em que indivíduos se envolvem em uma determinada prática, movidos por um interesse em comum (Jenkins, 2009).

Grande parte dos escritores de fanfictions (doravante ficwriters) está em idade escolar e engaja-se nesta atividade de produção textual em ambientes alheios à escola. Esta prática, que é despretensiosa e adotada voluntariamente pelos indivíduos, pode passar despercebida aos olhos dos educadores, ainda que apresente grande potencialidade para o ensino de línguas, de produção textual e de letramento crítico.

Diante do supracitado, o presente trabalho tem por objetivos:

- Mapear pesquisas com o uso de fanfictions para o ensino de Língua Inglesa; e

\footnotetext{
${ }^{2}$ Rede social fundada por Mark Zuckerberg em 2004, que ganhou grande popularidade no Brasil nos últimos anos. Conta com mais de 1 bilhão de usuários ativos em todo o mundo.

${ }^{3}$ Página disponível em $<$ https://www.facebook.com/DiariodeClasseSC?fref=ts $>$ Acesso em 16 de maio de 2015.
} 
- Identificar elementos ensináveis na literatura e em um material didático sobre o gênero fanfiction.

Para isso, o texto está organizado em quatro partes: a princípio, explicitamos o arcabouço teórico no qual nos baseamos; a seguir expomos os procedimentos metodológicos adotados; então apresentamos os dados obtidos e a análise dos mesmos; e então concluímos com nossas considerações finais.

\section{Referencial Teórico}

As fanfictions são textos pertencentes à esfera midiática e podem dar base à criação de comunidades discursivas. Não obstante, são também textos literários; e, como tais, trazem sua carga de subjetividade e refletem as características do contexto no qual o autor está inserido, bem como a sua relação com a narrativa originária. Este gênero, assim, alia duas forças: as narrativas são uma atividade de participação social em uma comunidade discursiva (Black, 2005) e expressões literárias, produtos e produtoras do meio social (Cândido, 2000).

Desta maneira, esta seção busca reunir três principais pilares teóricos: o gênero fanfiction; o ensino de língua inglesa; e vulnerabilidade social. Para isso, apresentaremos a seguir os construtos teóricos nos quais nos baseamos.

\subsection{Gênero Fanfiction e o Ensino de Língua Inglesa}

A gênese das fanfictions remonta a circulação de fanzines - as revistas criadas por fãs de determinado ícone midiático, de baixa tiragem e distribuição, que datam da década de 1970 (Vargas, 2005). Na contemporaneidade, não obstante, as fanfics circulam em comunidades virtuais de maneira quase irrestrita. Exemplo disso é o site Fanfiction.net ${ }^{4}$, atualmente um dos maiores sites de compartilhamento de fanfictions. Ele conta com um acervo gigantesco de histórias em diversos idiomas e de diversos ícones midiáticos, entre eles: livros, filmes, jogos, histórias em quadrinhos, desenhos animados e diversos outros. As narrativas originais dos ícones midiáticos são expandidas e exploradas cada vez mais e acabam por se tornar narrativas transmídias, (Versuti, Lima e Silva, 2012), isto é, transferem-se de suas mídias originais para diversas outras a fim de atenderem uma demanda do público e da comunidade de fãs.

As fanfictions estão inseridas nas atividades das comunidades de fãs conhecidas como fandoms ${ }^{5}$. Essas comunidades constroem uma identidade - sempre posta à prova pelos outros membros e constantemente reafirmada - que adquire valor dentro de seu contexto. É comum, por exemplo, ver o nome de identificação dos fandoms (potterheads,

\footnotetext{
${ }^{4} \mathrm{https}: / /$ www.fanfiction.net/

${ }^{5}$ Fandom é a junção das palavras fan e kingdom, provindas da língua inglesa: um reino de fãs.
} 
semideuses, tributos, etc $^{6}$ ) nos perfis de redes sociais. A integração à comunidade tornase parte da identidade do indivíduo de maneira e pode passar a defini-lo enquanto sujeito. $\mathrm{O}$ ato de escrever fanfiction - de ser um ficwriter - por sua vez, torna-se uma forma de participação social na comunidade do fandom: um espaço de interação social seguro e de interesses compartilhados (Black, 2005). Os indivíduos juntam-se nessas e em diversas outras comunidades motivados apenas pelas suas paixões, independentes de proximidades geográficas ou filiações institucionais (Lévy, 2008) e por isso podem abrigar e dar voz a indivíduos de diferentes gêneros, raças, idades, habilidades e escolaridades (Black, 2008).

Esse espaço social é deveras propício para o desenvolvimento linguístico, principalmente levando em consideração a abordagem vygotskiana do sociointeracionismo, segundo a qual o desenvolvimento linguístico se dá a partir da interação social em comunidades discursivas. Como concluiu Black (2005) a própria comunidade do fandom mantém o ambiente seguro para uma comunicação autêntica e livre, sem as barreiras e obrigações impostas pelo ambiente escolar. Como relata Massunaga (2013:15):

as comunidades de fãs também são um espaço para outras minorias, que vêem aí a possibilidade de compartilhar suas experiências com outras fãs. É claro que há conflitos, mas o que tenho percebido ao longo da minha própria experiência como fã que frequenta esses espaços é de que há muito mais solidariedade e um desejo verdadeiro de entender o outro do que hostilidade.

Rios-Registro e Almeida (2014) exploram o gênero fanfiction no que tange à sua aplicabilidade para o ensino de línguas e apontam três principais questões a serem exploradas: a sequência narrativa; os elementos literários; e os tipos de discurso. Black (2005), ademais, ainda afirma que a comunidade discursiva também se encarrega de fornecer o scaffolding ${ }^{7}$ necessário, o peer review (chamado de betagem nas comunidades de ficwriters e feito pelo beta-reader), a atividade metacognitiva acerca do ato de escrever e o feedback, mantendo um diálogo próximo e rápido entre autor e leitor. Esses elementos são fornecidos de maneira natural, não impostos, mas sim adotados mecanicamente.

\subsection{Fanfiction e o texto literário.}

\footnotetext{
${ }^{6}$ Tais nomes de identificação fazem alusão a um dos elementos presentes nas narrativas, tais quais: personagens, lugares, falas, etc.

${ }^{7}$ Optamos por manter em língua inglesa os termos que correspondem a conceitos teóricos já consolidados para o ensino de línguas estrangeiras ou termos técnicos do âmbito das tecnologias.
} 
Segundo Antônio Cândido (2000), todo texto literário carrega carga social na medida em que é, ao mesmo tempo, produto e produtor do meio social. Ou seja, a literatura reflete o contexto em que o autor estava inserido ao produzi-la, mas também repercute no meio social modificando-o. Esse meio social já modificado, por sua vez, refletir-se-á na produção de novas obras literárias. Diante do supracitado, entendemos que as fanfictions podem ser consideradas pertencentes à esfera literária, haja vista que, baseados em uma narrativa pré-existente, os ficwriters são influenciados pelo meio social no qual estão inseridos e impactam de alguma maneira no meio social em que circulam, mas também impactam no meio social em que os leitores estão inseridos. Tal processo pode ser abrangente e global, se pensarmos que a interação social em meio digital pode não estar restringida a barreiras que temos de enfrentar no mundo off-line, sejam elas físicas, sociais ou geográficas.

Além disso, a literatura pode servir de instrumento de representação e crítica da estrutura social e cultural, como por exemplo, 1984 de George Orwell, ou Admirável Mundo Novo de Aldous Huxley - ambos romances distópicos que propõem uma reflexão acerca dos sistemas políticos e das estruturas de dominação.

Segundo Anderson (2008), a literatura tem muito a oferecer na compreensão da relação de alteridade presente na sociedade. O movimento romântico brasileiro, por exemplo, criou um sentimento de pertencimento que unia cidadãos geograficamente distantes na primeira metade do século XIX, dando uma identidade para a brasilidade: o herói indianista. Com as fanfictions, este processo pode tornar-se global. As obras literárias, assim, constroem a identidade dos indivíduos na medida em que os definem como pertencentes a grupos distintos e os permitem enxergar a realidade do outro, ou através da realidade do outro. A literatura veste o leitor com óculos cujas lentes são a alteridade.

\subsection{Vulnerabilidade Social na Escola}

De acordo com Moita Lopes (2006) vulnerabilidade social é a situação de grupos cujas vozes são subjugadas socialmente em detrimento do discurso das elites, ficando à margem. Temos como exemplo: os pobres, os favelados, os negros, os indígenas, indivíduos homoeróticos, indivíduos em situação de dificuldades sociais, entre outros. $\mathrm{O}$ conhecimento de mundo dos indivíduos inseridos nesses grupos é tido como inferior e, por vezes, não é levado em consideração na construção do conhecimento.

Essa relação de subjugação turva a compreensão da própria relação de alteridade. Como clama o autor, essa compreensão faz parte de uma reinvenção do que se conhece por conhecimento científico e "ao mesmo tempo, um projeto social e epistemológico, ou talvez epistemológico porque social, diferindo muitas tradições que separavam a produção de conhecimento do ser social" (Moita Lopes, 2006:89). O ato de fazer ciência e construir conhecimento, então, assume um caráter também político. Tal reinvenção da 
vida social implica a reinvenção do que se entende por participação ou emancipação social: não apenas levar o conhecimento das elites a esses grupos socialmente vulneráveis, encarando-o como verdade; mas sim "construir a compreensão da vida social com eles em suas perspectivas e vozes, sem hierarquizá-los” (Moita Lopes, 2006:94-95). A prática da participação social, assim, refletir-se-ia na vida prática desses indivíduos, proporcionando-lhes oportunidades sociais que não teriam de outra maneira.

Abramovay e seus colaboradores (2002) apontam a vulnerabilidade social como fator causal da situação de violência e criminalidade sofrida pela juventude de países latino-americanos, por exemplo, haja vista que ela tolhe as oportunidades de acesso às estruturas de saúde, educação, trabalho, lazer e cultura. Essa situação de vulnerabilidade social, aliada à própria situação socioeconômica dos países, compromete os processos de integração social pelos quais essa juventude passa.

Visando combater essas situações, Paulo Freire sugere que a escola seja mola propulsora para que os indivíduos sejam capazes de reconfigurar suas realidades (Freire, 1987). Apesar disso, a escola pode acabar por agir em sentido oposto. Segundo Bourdieu e Passeron (1970), a escola serve às classes dominantes na medida em que se propõe a reproduzir as estruturas sociais vigentes e, por conseguinte, as diferenças sociais presentes nela, tais como as estruturas de dominação e as classes sociais. Ela "fornece a aparência de legitimidade às desigualdades sociais e sanciona a herança cultural e o dom social, tratado como dom natural". (Bourdieu, 1999:41). Assim, a escola tende a reforçar a situação de vulnerabilidade social na qual os indivíduos já se encontram e da qual podem não sair sem uma tomada de consciência: um ciclo vicioso. Para Bourdieu e Passeron, o primeiro contato dos alunos com as diferenças sociais na escola dá-se por meio dos diferentes capitais culturais trazidos ao ambiente escolar: diferentes origens, diferentes epistemes, diferentes maneiras de se consumir cultura e enxergar o mundo. É esse capital cultural, aliado ao sistema de valores dos cidadãos, que modelará suas atitudes em face aos diferentes capitais culturais e à própria instituição escolar. Desta maneira, a ideia de êxito na escola está intrinsicamente ligada à posição sócio-profissional e ao nível cultural de seus familiares e, portanto, ao contexto familiar no qual o aluno está inserido. A cultura das elites é a que traz recompensas na escola, que, tendo uma ação homogeneizante (todos alunos com iguais deveres e metas) mascara essa vantagem trazida pelo capital cultural transformando-a em meritocracia: o dom social tratado como dom natural. Desta maneira, a desigualdade social gera a desigualdade cultural.

Visando quebrar o ciclo, não obstante, Bourdieu (1999:53). sugere que a prática pedagógica deva ser:

[...] racional e universal, que partindo do zero e não considerando como dado o que apenas alguns herdaram, se obrigaria a tudo a favor de todos e se organizaria metodicamente em referência a um fim explícito de dar a todos os meios de adquirir aquilo que não é dado sob aparência de dom natural, senão às crianças de classes privilegiadas. 
O autor também clama ser necessário "desenvolver em todos os membros da sociedade, sem distinção, a aptidão para práticas culturais que a sociedade considera como as mais nobres" (Bourdieu, 1999:62). Assim, o aumento do capital cultural e social surge como um instrumento para combater a vulnerabilidade social (Abramovay et al, 2002), haja vista que promovem o estreitamento das relações simpáticas dos grupos sociais, ao mitigar as relações de violência e encorajar a ação coletiva. (Abramovay et al, 2002).

No que tange ao ensino de Língua Inglesa, Snyder (2009) sinaliza que os educadores do letramento são os responsáveis por fornecer aos alunos oportunidades para que eles possam se tornar navegadores críticos, ou seja, leitores críticos de textos digitais. Moita Lopes (2005) contribui para a discussão ao salientar que a globalização, apesar de aumentar consideravelmente o fluxo de conhecimento e cultura produzida em língua inglesa, é um processo de concomitante inclusão e exclusão, sendo que a exclusão linguística precede a exclusão digital, uma vez que tolhe dos indivíduos a oportunidade de participação no ciberespaço. Desta maneira, não basta que se tenha acesso aos aparelhos tecnológicos, mas que se aproprie das diferentes formas de comunicação e produzir sentido nesse meio. Ademais, Santos, Gamero e Gimenez (2014) apontam o inglês como indissociável da cidadania, principalmente tendo em mente o conceito de Cidadania Global, na qual os alunos ingressam através da apropriação da língua inglesa.

\section{Metodologia}

\subsection{Mapeamento de trabalhos}

Como parte dos objetivos deste trabalho e a fim de verificar o estado da arte no que tange às pesquisas acadêmicas sobre fanfictions, realizamos uma pesquisa qualitativa de análise documental. A busca foi realizada no Google Scholar, por meio de palavraschaves segundo os seguintes critérios:

- As palavras-chaves foram digitadas e a busca foi realizada em seguida. Então, o número de resultados foi anotado.

- Com as mesmas palavras-chaves, foi realizada uma nova busca utilizando aspas. Novamente, o número de resultados foi anotado.

- Todas as buscas foram realizadas conforme os dois critérios supracitados.

A primeira busca foi feita com as palavras-chave fanfiction, lingua inglesa e vulnerabilidade social e foram obtidos 18 resultados. A busca realizada com essas mesmas palavras-chave, porém com aspas ${ }^{8}$, não obteve nenhum resultado. Em seguida, foi realizada a busca com as palavras-chave fanfiction e vulnerabilidade social, na qual

\footnotetext{
${ }^{8}$ A pesquisa feita com aspas limita que a busca mostre apenas os resultados em que todas as palavraschaves estão presentes - ela diferencia-se da busca sem aspas pois esta exibe os resultados em que uma ou mais palavras-chaves estão presentes.
} 
foram obtidos 19 resultados. A busca com aspas obteve 3 resultados. A pesquisa seguinte foi realizada com as palavras-chave fanfiction e ensino de língua inglesa e obtivemos 77 resultados. A pesquisa com aspas resultou em 4 resultados. Por fim, foi realizada uma pesquisa que utilizou-se das palavras-chave participação social e fanfiction, na qual foram obtidos 242 resultados. A pesquisa com aspas resultou em 13 resultados.

Assim, optamos por utilizar as pesquisas resultantes das buscas realizadas com as palavras-chave fanfiction, língua inglesa e vulnerabilidade social; fanfiction e ensino de língua inglesa (com aspas) e fanfiction e participação social (com aspas).

De um total de 35 resultados, desconsideramos 24 resultados que fugiam ao tema e 4 que se repetiam em pelo menos uma das pesquisas. Cruzando, então, as pesquisas, chegamos a uma lista de 7 trabalhos, listados na seção 4.1.

\subsection{Proposta Didática}

No que tange ao segundo objetivo, "identificar elementos ensináveis na literatura e um material didático sobre o gênero fanfiction", cruzamos as categorias emergidas da literatura com os textos utilizados em uma sequência didática produzida pelo autor, Felipe Trevisan Ferreira, em colaboração com os alunos do curso de Letras-Inglês da Universidade Estadual de Londrina, Paola Rodrigues Figueira e Roberto Yendo, elaborada como parte das atividades da disciplina de Gêneros deste curso de graduação 9 . Os elementos ensináveis do gênero são analisados por meio das atividades desenvolvidas e dos textos utilizados na sequência didática.

Em um primeiro momento, nossa intenção era implementar uma oficina de escrita de fanfictions em Língua Inglesa em contextos de vulnerabilidade social da cidade de Londrina, utilizando a sequência didática anteriormente citada. O trabalho de Lemes e Cristovão (no prelo) ${ }^{10}$ revelou que a região norte de Londrina possui o maior número de pré-adolescentes, adolescentes e jovens assistidos por ações socioassistenciais (como o IRSAS $^{11}$ ). Orientados por esta pesquisa, firmamos parceria com o Centro Cultural Lupércio Luppi, localizado na região norte de Londrina, a fim de atender os jovens da região. Não obstante, nosso trabalho foi inviabilizado pouco antes do início da oficina devido a uma pane nos computadores do Centro Cultural, os quais permaneceram no aguardo de suporte técnico até o encerramento desta pesquisa. Tentamos, ainda, uma posterior implementação do material desenvolvido em uma das escolas cujos alunos eram atendidos pelo Centro Cultural, mas fomos impedidos pela greve dos servidores e

\footnotetext{
9 A sequência didática não é apresentada aqui por não ser este o objetivo do presente trabalho. Todavia, uma apresentação e descrição completa poderá ser encontrada no texto de Adati, Trevisan Ferreira e Cristóvão (2017).

${ }^{10}$ Projeto "Grupos socialmente vulneráveis do município de Londrina: mapeamento e possibilidade de participação social” desenvolvido do período 08/2013 - 07/2014.

${ }^{11}$ Informatização de Rede de Serviços da Assistência Social
} 
professores das escolas estaduais do Paraná nos períodos de fevereiro a março de 2015 e de abril a junho de 2015.

Desta maneira, nossa análise se limita ao material didático desenvolvido, uma vez que sua implementação na sala de aula ainda não ocorreu de fato. Apesar das dificuldades enfrentadas pelo projeto, novas tentativas de implementação da oficina de fanfictions serão realizadas, de modo a investigar as práticas discursivas e de participação social de alunos em situação de vulnerabilidade social e fomentar pesquisas vindouras.

\section{Apresentação e Análise dos Resultados. \\ 4.1 Mapeamento de Trabalhos.}

O quadro a seguir lista os trabalhos encontrados no Google Scholar seguindo os critérios de pesquisa anteriormente descritos:

Quadro 1 - Trabalhos sobre fanfictions.

\begin{tabular}{|c|c|c|c|}
\hline Autor & Título & Local & Nível \\
\hline $\begin{array}{l}\text { ALVES, E. C. } \\
\text { A. }\end{array}$ & $\begin{array}{c}\text { Um Estudo Sobre } \\
\text { Fanfiction: A Leitura e a } \\
\text { Escrita no Ambiente Digital }\end{array}$ & UFMT & $\begin{array}{l}\text { Artigo publicado em } \\
\text { revista (Eventos } \\
\text { Pedagógicos). }\end{array}$ \\
\hline $\begin{array}{l}\text { COSTA, P. S. } \\
\text { C. e } \\
\text { REATEGUI, E. } \\
\text { B. }\end{array}$ & $\begin{array}{c}\text { O Papel das Ferramentas } \\
\text { Digitais no Letramento } \\
\text { através de Narrativas } \\
\text { Fanfiction }\end{array}$ & UFRGS & $\begin{array}{l}\text { Artigo em Revista } \\
\text { (CINTED - } \\
\text { UFRGS) }\end{array}$ \\
\hline $\begin{array}{l}\text { MAGNONI, A. } \\
\text { F. e } \\
\text { MIRANDA, G. } \\
\text { V. }\end{array}$ & $\begin{array}{c}\text { Novas Formas de } \\
\text { Comunicação no Século } \\
\text { XXI: O Fenômeno da } \\
\text { Cultura Participativa }\end{array}$ & $\begin{array}{l}\text { Universidade } \\
\text { Estadual } \\
\text { Paulista }\end{array}$ & $\begin{array}{l}\text { Artigo em revista } \\
\text { (Conexão - } \\
\text { Comunicação e } \\
\text { Cultura, UCS, } \\
\text { Caxias do Sul). }\end{array}$ \\
\hline $\begin{array}{l}\text { BARCELLOS, } \\
\text { P. }\end{array}$ & $\begin{array}{c}\text { Mineração Textual e } \\
\text { Produção de Fanfictions: } \\
\text { Processos Desencadeadores } \\
\text { de Oportunidades de } \\
\text { Letramento no Ensino de } \\
\text { Língua Estrangeira }\end{array}$ & UFRGS & Tese de doutorado \\
\hline $\begin{array}{c}\text { MASSUNAGA, } \\
\text { A. P. }\end{array}$ & $\begin{array}{c}\text { Construções Discursivas } \\
\text { Situadas Sobre Práticas } \\
\text { Sociais de Fãs em } \\
\text { Ambientes Virtuais }\end{array}$ & UFRJ & $\begin{array}{l}\text { Dissertação de } \\
\text { Mestrado }\end{array}$ \\
\hline KOREN, N. B. & $\begin{array}{l}\text { O Fã de Fã: Um Estudo da } \\
\text { Relação entre Leitores e }\end{array}$ & UFRGS & Monografia / TCC \\
\hline
\end{tabular}




\begin{tabular}{|c|c|l|l|}
\hline & $\begin{array}{c}\text { Ficwriters no Site } \\
\text { Fanfiction.net }\end{array}$ & \\
\hline CARDOSO, T. & Quando a Produção e a & UFRGS & Monografia / TCC \\
C. A. & $\begin{array}{c}\text { Recepção se Entrelaçam: } \\
\text { Um Estudo de Caso do } \\
\end{array}$ & & \\
& Fenômeno Literário & & \\
& Cinquenta Tons de Cinza & & \\
\hline
\end{tabular}

Fonte: os autores

Alves (2014) aponta as fanfictions como um meio de letramento digital e ainda salienta a necessidade crescente de se investigar as práticas de letramento nas quais os alunos estão engajados fora do ambiente escolar, de modo a entender as maneiras pelas quais estas possam ser incorporadas à educação. Costa e Reategui (2010) acrescentam que uma proposta didática que utilize o gênero em questão a partir de softwares para a criação de grafos (como o SOBEK, utilizado pelos autores) pode dar suporte à participação dos alunos em atividades de leitura e produção textual de maneira ativa e autônoma. Essa possibilidade ainda foi ratificada pela tese de Barcellos (2013) que, a partir da utilização do SOBEK, constatou que o letramento em língua estrangeira foi fomentado pelo uso de fanfictions.

Magnoni e Miranda (2013), por outro lado, tiveram um enfoque mais voltado às práticas das comunidades de fãs e criação da cultura no ciberespaço. Eles constataram que o gênero é, ao mesmo tempo, uma resposta à indústria cultural e uma forma de participação social, apesar de sua despretensão. É também nesse viés que se encaixa a dissertação de Massunaga (2013), que ao investigar as construções discursivas do universo de fãs, pode perceber que as práticas situadas no ciberespaço são diversificadas, influenciando e sendo influenciadas pelo mundo off-line, de maneira análoga à supracitada relação da literatura com a sociedade, teorizada por Antônio Cândido (2000). Ademais, Massunaga (2013) também afirma que o ciberespaço é democrático na medida em que vozes de diferentes culturas e classes sociais podem dialogar independentemente de afiliações institucionais, especialmente as vozes de grupos socialmente subjugados.

Koren (2012), por sua vez, analisou a interação entre ficwriters e leitores, concluindo que esta é mais direta e interativa do que a relação entre o fã e o objeto midiático, uma vez que as mensagens dos leitores podem chegar ao ficwriter imediatamente e, por vezes, antes de o texto estar concluído, influenciando-o. Seguindo essa linha de pesquisa, Cardoso (2013) visou explorar as novas possibilidades de circulação e produção textual trazidas pelas fanfictions. Para isso, analisou a trilogia "Cinquenta Tons de Cinza"12 e constatou que a mesma implica uma relação espiral, na

\footnotetext{
12 Trilogia de romances eróticos best-seller escrita por E. L. James que foi publicada inicialmente como uma fanfiction da série infanto-juvenil "Crepúsculo" e posteriormente adaptada para o mercado editorial.
} 
qual o produto acaba por se tornar o próprio ícone midiático, movimentando a esfera da produção cultural.

Podemos observar que a maior parte das pesquisas em âmbito nacional sobre fanfictions em contextos educacionais centra-se nas regiões sul e sudeste. A universidade com maior número de publicações nesse tema é a UFRGS, revelando uma região de concentração de interesses. Ademais, a maior parte das pesquisas é de cunho bibliográfico e metodológico. Não foi encontrado nenhum trabalho que relacionasse o uso de fanfictions a contextos educacionais de vulnerabilidade social. O fenômeno fanfiction, pode-se dizer, vem sendo estudado como uma prática de letramento em meio digital e como agente da chamada "cultura de convergência"13 (Jenkins, 2009).

Apesar de a pesquisa sobre o gênero fanfiction ainda ser jovem no meio acadêmico (o trabalho mais antigo encontrado data do ano de 2010), podemos notar que trata-se de um fenômeno complexo e com inúmeras características distintas a serem investigadas em pesquisas vindouras. Ademais, é uma prática deveras comum entre os jovens em idade escolar (Black, 2005) e pode ser usada como um instrumento de letramento digital. Fica, assim, evidente a necessidade de que busquemos compreender as práticas sociais discursivas nas quais os alunos engajam-se fora do ambiente escolar, a fim de que possamos construir um ensino que leve em consideração os estudantes enquanto indivíduos com práticas culturais próprias.

\subsection{Elementos Ensináveis do Gênero.}

Os elementos ensináveis são identificados por meio da construção de um modelo didático de gênero o qual possibilita a "visualização das dimensões constitutivas do gênero e seleção das que podem ser ensinadas e das que são necessárias para um determinado nível de ensino" (Machado e Cristovão, 2010:557). Para essa construção, é necessário mapear as condições do contexto didático, considerar as características do gênero expressas por referências de especialistas e analisar conjunto de textos considerados como pertencentes ao gênero e adequados ao contexto didático estudado.

Enquanto Lemes e Cristovão (no prelo) mapearam a localização e condições de grupos de adolescentes e jovens em situação de vulnerabilidade no município em questão, Rios-Registro e Almeida (2014) categorizaram elementos ensináveis do gênero fanfiction em três principais grupos, a saber: sequência narrativa; temática e elementos literários e tipos de discurso, considerando tanto pesquisas já realizadas quanto exemplares do gênero. Usaremos os textos utilizados na sequência didática produzida em uma disciplina do curso de formação inicial de professores de inglês a fim de explorar tais elementos.

\footnotetext{
${ }^{13}$ A cultura da convergência, teorizada por Henry Jenkins em 2009, se refere ao processo segundo o qual as narrativas circulam na contemporaneidade, transportando-se por diversas mídias distintas de modo a atender a demanda de um determinado público.
} 


\subsubsection{Sequência Narrativa}

Como apontado por Rios-Registro e Almeida (2014), as fanfictions possuem uma sequência narrativa própria composta por: a) situação inicial, a qual se caracteriza pela apresentação dos espaços e personagens da narrativa; b) complicação, indica o conflito ou seja as ações necessarias para o desenvolvimento da historia; c) resolução, representado pela conclusão do conflito; d) situação final, é a fase em que os personagens são apresentados a uma nova situação que resulta da resolução do conflito. Não obstante as fanfictions também se relacionam com a narrativa do ícone midiático. Isto é, o ficwriter se apropria de uma narrativa já existente para elaborar uma nova narrativa.

A fanfiction "Cat Lady", análise, está situada após o desfecho da narrativa do livro "A Esperança”, que encerra a série do ícone midiático Jogos Vorazes. Apesar de situar-se em um momento específico da narrativa original, uma nova sequência narrativa é criada a fim de atingir os propósitos do autor. Deste modo pode-se exemplificar na fanfiction supracitada as partes da sequência narrativa por:

a) Situação inicial: "Eu ando pela Aldeia dos Vitoriosos. Já faz algum tempo desde que saí de casa. É uma sensação boa, mas, apesar de o Distrito Doze estar sendo reconstruído por completo, há recordações dela por toda a parte." ${ }^{, 15}$

b) Complicação: "Eu franzo o cenho quando ouço um grito de dor vindo de um gato. Eu a pego no colo. Normalmente, eu não faria nada para ajudar um animal. Mas eu sou uma pessoa diferente agora. E me incomoda às vezes quando vejo criaturas sofrendo. Eu examino o gato. É uma menina. Muito de seu pelo branco está manchado de vermelho por causa do sangue. Eu procuro pela ferida. A gata foi mordida na pata. Talvez por um cachorro ou algum animal selvagem que conseguiu passar pela cerca. Eu não acho que essa gata tem comido o suficiente, também." "16

c) Resolução: "Eu vou para a cozinha e coloco a gata na mesa, onde Gale esteve ferido e sangrando um ano atrás. Eu franzo o cenho. Não sei ao certo o que fazer agora. Eu olho nas gavetas. E acho remédio de gente. Mas não sei se é seguro usá-lo em gatos. Eu lavo o sangue da gata e coloco uma bandagem em sua pata. Eu procuro por sobras de comida na geladeira, e as coloco na frente dela. Ela levanta lentamente e pega as sobras."17

\footnotetext{
${ }^{14}$ Disponível em <https://www.fanfiction.net/s/10609173/1/Cat-Lady> . Acesso em: 16 de maio de 2015.

${ }^{15}$ Nossa tradução para: "I walk through the Victors Village. It's been a while since I went outside. It feels nice, but, even though District Twelve is being remade completely, there are reminders of her everywhere."

${ }^{16}$ Nossa tradução para: "I frown when I hear a pained sound coming from a kitten. I pick the creature up. Normally I wouldn't do anything to help an animal. But I'm a different person now. And it bothers me sometimes when I see living things hurt. I examine the cat. It's a girl. A lot of her white fur is stained red with blood. I look for the wound. The cat has been bitten on her leg. Maybe by a dog or some wild animal that got over the fence. I don't think this cat has been eating enough, either"

${ }^{17}$ Nossa tradução para: "I walk to the kitchen and set the cat on the table, where Gale was hurt and bleeding a year ago. I frown. I'm not sure what to do now. I search through the cabinets. And find some medicine
} 
d) Situação final: "Eu a observe cuidadosamente e mudo de ideia. Talvez eu não a devolverei se ela tiver um dono"18

Ao levar, assim, o texto para a sala de aula, é possível que o professor o apresente de maneira a aproximá-lo dos alunos, isto é, fora de um pedestal intocável, onde os alunos o alcançarão e poderão se apropriar dele (Rios-Registro e Almeida, 2014). Ao fazê-lo, pode fomentar uma reflexão acerca dos processos de construção linguística e de que maneira eles se relacionam com os efeitos de sentido provocados no leitor.

\subsubsection{Temática e Elementos Literários}

Rios-Registro e Almeida (2014) caracterizam a fanfiction como uma extensão do gênero "romance". Ela resguarda certas características da esfera em que a narrativa do ícone midiático circula, mas também possui características distintas, próprias da plataforma em que circula, tais quais: imagens, disclaimer, perfil do autor, classificações específicas de gênero, tamanho, temática, entre outros. As autoras ressaltam que, para a produção de uma fanfiction com sucesso, o autor deve dominar a temática, isto é, o universo ficcional da trama originária e seu plano sequencial. Da mesma maneira, a produção de um texto desse gênero está condicionada à utilização coesa e coerente dos elementos literários, uma vez que as fanfictions são indissociáveis de elementos como tempo, espaço, enredo e personagens.

A criação de uma fanfiction implica uma apropriação de uma narrativa préexistente, e, portanto, em uma apropriação de seus elementos e tema, que são modificados e adaptados ao novo suporte de acordo com as intenções dos autores. Ao levar esta prática para a sala de aula, os alunos podem refletir acerca dos elementos da narrativa original de modo a entendê-la e se apropriar dela para a criação de uma nova história.

Figura 1: Atividade Temática da Sequência Didática

"The man lived in a state of hyper-vigilance and was often known to hex first and ask questions later" (Paranoia, Caz251)

O que levou Moody a viver nesse estado de vigilância constante ? Qual impacto isso pode ter no modo como ele vive e compreende o mundo bruxo? Você acha que em nossa sociedade existem pessoas vivendo também em um estado de Vigilância Constante? Por quê? Você conhece alguém assim? Como isso afeta a vida das pessoas?

for people. But I don't know if it's safe to use on cats. I wash the blood from the cat and bandage her leg. I search the fridge for leftovers, and put it in front of her. She stands up slowly and picks at the leftovers." ${ }^{18}$ Nossa tradução para: "I watch her carefully and change my mind. Maybe I won't give her back if she has an owner." 
Ademais, ao apropriar-se da narrativa do ícone midiático, o aluno adiciona sua voz à voz do autor e com isso reflete acerca do contexto sociocultural no qual está inserido. Esse processo pode ser estimulado em sala de aula, como sugerido na figura 1, que ilustra uma das atividades presentes na sequência didática em análise.

\subsubsection{Tipos de Discurso}

As fanfictions, uma vez que pertencem à esfera literária, são linguisticamente complexas e possuem diferentes estruturas léxico-gramaticais. Rios-Registro e Almeida apontam que os textos deste gênero "demonstram disjunção quanto ao mundo discursivo" (Rios-Registro e Almdeira, 2014:240), isto é, os fatos que são representados nas narrativas são alheios à situação de produção.

A fanfiction supracitada "Cat Lady", por exemplo, apresenta uma grande diversidade de tempos verbais no tipo de discurso da narração, entre eles: present simple ("I walk through de Victors Village..." "It feels nice..."), present perfect ("It's been a while..."), present continuous ("...is being remade”) e past perfect ("I hadn't thought..."). O mesmo é verdade para a fanfiction "The Cry of The Mockingjay 19 ", também presente no material didático em análise, uma vez que o texto conta com verbos no present simple ("I want you to be happy"), past simple ("I sat next to dad"), past continuous ("He was dieing of cancer"), past perfect ("He said he had found it"), entre outros, todos pertencentes à ordem do narrar.

Figura 2: Atividade Léxico-Gramatical da Sequência Didática

b) Baseando-se nas informações do exercício a, responda: quais são os tempos verbais mais usados nos livros de Hunger Games? E nas fanfictions? Qual é o efeito dessa escolha gramatical para o enredo?

Além do próprio ensino de estruturas léxico-gramaticais, o professor pode fomentar no aluno uma reflexão acerca dos efeitos de sentido provocados no leitor na ${ }^{19}$ Disponível em <https://www.fanfiction.net/s/10609047/1/Cry-Of-The-Mockingjay $>$ Acesso em $16 \mathrm{de}$
maio de 2015. 
construção da narrativa literária, tanto no ícone midiático quanto na narrativa da fanfiction. Exemplificamos isto na figura 2, retirada da sequência didática em análise.

\section{Considerações Finais}

Este trabalho tem por objetivos: a) mapear pesquisas com o uso de fanfictions para o ensino de Língua Inglesa e; b) identificar elementos ensináveis na literatura e em um material didátco sobre o gênero fanfiction. Diante do apresentado, podemos concluir que o material didático abordou, de fato, os três principais elementos ensináveis do gênero fanfiction: sequência narrativa, temática e elementos literários e tipos de discurso. Ademais, pode-se afirmar que o fenômeno fanfiction apresenta diversas potencialidades ao ensino de línguas. É uma prática social e discursiva com inúmeros vieses a serem investigados, especialmente se pensarmos em sua relação com os novos letramentos. Fazse assim real a necessidade de vindouras pesquisas na área, de modo a entender a prática de fãs e suas especificidades na transposição para a sala de aula.

Todavia, a dificuldade de implementação do projeto pode revelar uma situação distinta daquela apontada pelos trabalhos encontrado no mapeamento. A situação que encontramos nos parece deveras paradoxal: os indivíduos em situações de vulnerabilidade social, aqueles que têm suas vozes subjugadas e silenciadas no mundo off-line (Moita Lopes, 2006) sequer têm acesso ao ciberespaço, onde poderiam apropriarse de diversos gêneros, produzirem textos e serem ouvidos, uma vez que o ciberespaço afirma-se cada vez mais como um espaço democrático - além de terem a possibilidade de entrar em contato com vozes de diferentes partes do mundo, fazendo parte de uma comunidade global (Massunaga, 2013). Nessa situação, a exclusão socioeconômica parece causar a exclusão cultural no ciberespaço. Os indivíduos que pertencem às elites socioeconômica, por outro lado, podem ter acesso ao ciberespaço sem maiores problemas.

Longe de oferecer todas as respostas e soluções para as situações apresentadas, buscamos chamar a atenção e levantar mais questionamentos e provocações nos leitores - inclusive para a elaboração de pesquisas vindouras - para que possamos entender coletivamente as relações de poder presentes nas práticas discursivas nas quais os alunos se engajam (ou poderiam se engajar) e de que maneira isto se relaciona - ou, mais importante, poderia se relacionar - com a nossa prática pedagógica.

\section{Referências bibliográficas}

ABRAMOVAY, M.; CASTRO, M. G.; PINHEIRO, L. C.; LIMA, F. S.; MARTINELLI, C. C. 2002. Juventude, violência e vulnerabilidade social na América Latina: desafios para políticas públicas. Brasília: UNESCO, BID.

ADATI, F.; TREVISAN FERREIRA, F.; CRISTÓVÃO, V. L. L. 2017. O uso de gêneros da esfera digital em contextos de vulnerabilidade social: duas propostas de sequência 
didática. In: EL KADRI, M. S.; ORTENZI, D. I. G.; RAMOS, S. G. M. (Orgs) 2017. Tecnologias digitais no ensino de línguas e na formação de professores: reorganizando sistemas educacionais. Campinas, SP : Pontes Editores, ISBN 978-85-7113.

ALVES, E. C. A. 2014. Um Estudo Sobre Fanfiction: a leitura e a escrita no ambiente digital. Eventos Pedagógicos, v. 5, p. 38-47.

ANDERSON, B. 2008. Comunidades Imaginadas. São Paulo. Cia das Letras.

BARCELLOS, P. S. C. C. 2013. Mineração textual e produção de fanfictions: processos desencadeadores de oportunidades de letramento no ensino de língua estrangeira. Tese de Doutorado. Universidade do Rio Grande do Sul. Porto Alegre.

BLACK, R. W. 2005. Access and affiliation: The literacy and composition practices of English-language learners in an online fanfiction community. Journal of Adolescent and Adult Literacy, v. 49, n. 2.

2008. Adolescents and online fanfiction. New York: Peter Lang Publishing.

BOURDIEU, P. A. 1999. Escola Conservadora: as desigualdades frente à escola e à cultura. In NOGUEIRA, M. A.; CATANI, A. Escritos de Educação. 2 ed. Petrópolis: Vozes.

.; PASSERON, J. C. 1970. A Reprodução: elementos para uma teoria do sistema de ensino. 3. ed. Rio de Janeiro: Francisco Alves.

CÂNDIDO, A. 2000. Literatura e Sociedade: estudos de teoria e história literária. $8^{\mathrm{a}}$. ed. São Paulo: T. A. Queiroz.

CARDOSO, T. C. A. 2013. Quando a produção e a recepção se entrelaçam: um estudo de caso do fenômeno literário Cinquenta Tons de Cinza. Monografia. Universidade Federal do Rio Grande do Sul, Porto Alegre,

COSTA, P. S. C.; REATEGUI, E. B. 2010. O papel das ferramentas digitais no letramento através de narrativas fanfiction. CINTED (UFRGS) v.8, n.2.

FREIRE, P. 1987. Pedagogia do Oprimido. Ed. Rio de Janeiro: Paz e Terra.

JENKINS, H. 2009. Cultura da Convergência. Tradução de Susana Alexandria. São Paulo: Aleph.

KOREN, N. B. 2012. O Fã de Fã: um estudo da relação entre leitores e ficwriters no site fanfiction.net. Monografia. Universidade Federal do Rio Grande do Sul, Porto Alegre.

LEMES, T.; CRISTOVÃO, V.L.L. (no prelo). Grupos socialmente vulneráveis do município de Londrina: mapeamento e possibilidade de participação social.

LÉVY, P. 2008. Cibercultura. Trad. Carlos Irineu da Costa. São Paulo: Editora 34.

MAGNONI A. F. ; MIRANDA, G. V. 2013. Novas formas de comunicação no século XXI: o fenômeno da cultura participativa. Conexão - Comunicação e Cultura, v. 12, n. 23.

MACHADO, A. R.; CRISTOVÃO, V. L. L. 2010. A construção de modelos didáticos de gêneros: aportes e questionamentos para o ensino de gêneros. Linguagem em (Dis)curso, [S.1.], v. 6, n. 3, p. p. 547-573, out. ISSN 1982-4017. Disponível em: $<$ http://portaldeperiodicos.unisul.br/index.php/Linguagem_Discurso/article/view/349/37 0>. Acesso em: 27 maio 2017.

MASSUNAGA, A. P. 2013. Construções discursivas situadas sobre práticas sociais de fãs em ambientes virtuais. Dissertação de Mestrado. Universidade Federal do Rio de Janeiro, Rio de Janeiro.

MOITA LOPES, L.P. 2005. Inglês no mundo contemporâneo: ampliando oportunidades sociais por meio da educação. Texto-base do Simpósio da TIRF (TESOL International Research Foundation), realizado em São Paulo, mimeo. 
2006. Linguística Aplicada e Vida Contemporânea: Problematização dos Construtos que têm Orientado a Pesquisa. In.: (Org.) 2006. Por uma Linguìstica Aplicada Indisciplinar. São Paulo: Parábola Editorial.

RIOS-REGISTRO, E. S.; ALMEIDA, D. 2014. Fanfiction: elaboração de uma proposta didática do gênero. In: EL KADRI, M. S.; PASSONI, T. P.; GAMERO, R. (Orgs) 2014. Tendências contemporâneas para o ensino de língua inglesa: propostas didáticas para a educação básica. Campinas: Ed. Pontes.

SANTOS, L. M. A.; GAMERO, R. e GIMENEZ, T. 2014. Letramentos digitais, interdisciplinaridade e aprendizagem de língua inglesa por alunos do ensino médio. Trabalhos em Linguística Aplicada, v. 53, p. 79-102,

SNYDER, I. 2009. Ame-os ou deixe-os: navegando no panorama de letramentos em tempos digitais. In: ARAÚJO, J. C.; DIEB, M. (org.) 2009. Letramentos na Web: gêneros, interação e ensino. Fortaleza: Edições UFC..

VARGAS, M. L. B. 2005. O fenômeno fanfiction: novas leituras e escrituras em meio eletrônico. Passo Fundo: Ed. Universidade de Passo Fundo.

VERSUTI, A. C.; LIMA, D. J.; SILVA, D. D. A. 2012. O potencial das fanfics baseadas em Star Wars para a Educação. VI Colóquio Internacional "Educação e Contemporaneidade", São Cristóvão.

Felipe Sousa Adati is graduated in English Language Teaching and Literature from the State University of Londrina (2016). He was part of the research group Language and Education (2014-2016) and PIBID (CAPES) program (2014-2016) working with researchers focused on teaching languages through the use of new technologies. His research areas of interest are: technologies for second language teaching, games and gamification.E-mail:felipesousa adati@hotmail.com

Felipe Trevisan Ferreira is an English Teacher graduated in English Language Teaching and Literature from Londrina State University (2016). He was part of the PIBID-CAPES program (2013-2015) and developed a Scientific Initiation research as part of the "Language \& Society" project (2015). His research interests are: New Literacies, Social Participation, Sexuality and Gender Diversity. E-mail: trevisanfelipe5@gmail.com

Vera Cristovão, Associate Professor of English at the State University of Londrina, Paraná, Brazil, teaches for undergraduate and graduate levels and carries out research for the Brazilian National Council for Scientific and Technological Development. She has co-edited books and written many articles and chapters of books on genre studies, teacher education and foreign language teaching and learning. As an English teacher, she has currently focused her work on writing and genre studies. E-mail: veraluciacristovao@gmail.com 